\title{
DIETARY HABITS AND MYOCARDIAL INFARCTION IN OCCUPATIONALLY ACTIVE MEN
}

\author{
ALICJA BORTKIEWICZ ${ }^{1}$, ELŻBIETA GADZICKA ${ }^{1}$, JADWIGA SIEDLECKA ${ }^{1}$, AGATA SZYJKOWSKA ${ }^{1}$, \\ PIOTR VIEBIG ${ }^{1}$, JERZY KRZYSZTOF WRANICZ², MALGORZATA KURPESA ${ }^{3}$, EWA TRZOS ${ }^{3}$, \\ and TERESA MAKOWIEC-DĄBROWSKA ${ }^{1}$
}

${ }^{1}$ Nofer Institute of Occupational Medicine, Łódź, Poland

Department of Work Physiology and Ergonomics

${ }^{2}$ Medical University of Lodz, Łódź, Poland

Department of Electrocardiology

${ }^{3}$ Medical University of Lodz, Łódź, Poland

Department of Cardiology

\begin{abstract}
Objectives: Only a few studies have been undertaken to analyze the dietary habits of people with cardiovascular diseases. The aim of this study was to evaluate the dietary behaviors of working people who were hospitalized due to experiencing the first acute cardiovascular incident. Material and Methods: In the study, the Functional Activity Questionnaire was used. The study was conducted in 2 groups. The first group included all the men hospitalized during 1 year (January-December 2009) in 2 clinics of cardiology, who were professionally active until the first myocardial infarction (MI). It comprised 243 men aged 26-70 years. The reference group consisted of 403 men, blue- and white-collar workers, aged 35-65 years. Results: The body mass index of the MI patients was significantly higher $(\mathrm{p}=0.006)$. The frequency of consumption of particular products in the MI group and in the reference group differed significantly for 11 of 21 products. The MI patients significantly less frequently reported the daily consumption of fruit, raw vegetables, cheese, vegetable oils and fish. In this group, the consumption of salty $(p=0.0226)$ or fatty $(p<0.0001)$ foods was significantly higher. It was shown that, after adjusting for age, education and the type of work, the daily consumption of fish, salads and cooked vegetables, as well as fruit and vegetable oils, significantly reduced the risk of myocardial infarction. An increased MI risk was, in turn, associated with obesity and preference for fatty foods. Conclusions: The authors found that diet significantly modified the MI risk in the examined workers. This indicates that an important aspect of prevention activities among working people should involve education about proper dietary habits. Int J Occup Med Environ Health. 2019;32(6):853-63
\end{abstract}

Key words:

nutrition, food, acute myocardial infarction, physical work, mental work, body mass index

\section{INTRODUCTION}

Improper diet is one of the classic, modifiable risk factors for cardiovascular diseases (CVDs). The principles of healthy dietary habits recommended by scientific bodies involve the right choice of products from different food groups, in accordance with the Pyramid of Healthy Nutrition and Physical Activity [1]. According to these principles, promoted in Poland by the National Food and Nutrition Institute, vegetables and fruit (in the correct proportions: three-fourths of vegetables and one-fourth

Funding: this work was based on the results of a project co-financed by the European Union under the European Social Fund: Human Capital Programme (project No. WND-POKL 02.03.01-00-001/08, entitled "Development of comprehensive prevention programs," project manager: Prof. Jolanta Walusiak-Skorupa). Received: May 16, 2019. Accepted: August 14, 2019.

Corresponding author: Alicja Bortkiewicz, Nofer Institute of Occupational Medicine, Department of Work Physiology and Ergonomics, św. Teresy 8, 91-348 Łódź, Poland (e-mail: alab@imp.lodz.pl). 
of fruit) accounting for at least a half of the daily food rations should form the basis of proper nutrition. Vegetables and fruit are a source of numerous valuable minerals, vitamins and polyphenols, and they significantly reduce the morbidity and mortality attributable to CVDs, diabetes and cancer.

The daily food rations should include cereals (whole-grain in particular), milk and/or dairy products. At the same time, a moderate consumption of meat is recommended. It is further considered desirable to replace meat with fish, legumes and eggs, and to use vegetable oil instead of animal fat. A moderate consumption of sugar and sweets, along with a limited intake of salt, is also recommended [1]. However, it is daily physical activity for at least 30-45 min that constitutes the foundation of the new pyramid. Combined with a well-balanced diet, it can prevent, among other things, the development of overweight and obesity.

A spectacular example is Finland where mortality from the ischemic heart disease fell by $55 \%$ in men and by $68 \%$ in women over the years 1972-1992. Studies have shown that this effect is in $75 \%$ explainable by changes in the level of risk factors, and the reduction of serum cholesterol levels in particular. This decrease in mortality was possible owing to changes in the energy balance; the contribution of energy from fat to the total energy intake dropped from $38 \%$ to $34 \%$, including the change for saturated fat from $21 \%$ to $16 \%$, and polyunsaturated fat from $3 \%$ to $5 \%$, and a reduction of the consumption of cholesterol by $16 \%$. During that period, the consumption of fruit doubled, while that of vegetables tripled. These changes in diet, coupled with a reduction of tobacco smoking and a better control of blood pressure, contributed to such a significant decrease in the mortality in Finland [2].

The results of many epidemiological studies suggest that a lower risk of atherosclerosis and CVDs prevails in the populations following Mediterranean-like diets including grains, legumes, vegetables and fruit [3].
The impact of different types of diets on the CVD risk and various causes of death was investigated in a metaanalysis by Schwingshack and Hoffmann in 2015 [4]. The analysis included the following types of diets: the Healthy Eating Index (HEI), the Alternate Healthy Eating Index (AHEI), and the Dietary Approaches to Stop Hypertension (DASH). The meta-analysis covered 4 cohort clinical studies on all causes of death, 12 studies on cardiovascular diseases, 6 studies on cancer, 6 studies on type 2 diabetes, and 2 studies on neurodegenerative diseases. The effectiveness of all analyzed diets has been shown to be statistically significant: $45 \%$ for cardiovascular diseases and $77 \%$ for cancer. However, there was no significant effect of diet on the prevalence of Parkinson's disease.

The recently published results of a prospective study on 29343 male participants of the Health Professionals Follow-up Study and 51195 women participating in the Nurses' Health Study (1986-2010) were used to compare the effects of different diets (AHEI, DASH, AMED) on the CVD risk. During 1394702 person-years of observation, 11793 cases of CVDs were recorded. It was found that the effectiveness of these types of diets was similar; the CVD risk was reduced during each 4-year period by $7-8 \%$. At the same time, the deterioration in the quality of the diet resulted in a significant increase in the CVD risk [5]. Similar results were obtained by Menotti et al. [6-8]. They analyzed the morbidity and mortality from cardiovascular diseases and cancer, depending on the diet, and demonstrated that the Mediterranean diet tended to reduce the CVD risk.

Although the favorable changes in the mortality from CVDs in Poland were observed in the last 20 years, cardiovascular diseases continue to be the leading cause of death (NATPOL 2011), and the mortality rate is constant at a level of approx. 45\% [9-11]. One of the reasons could be an improper diet, because the current dietary habits of Poles differ from those recommended by nutrition experts. One in 5 adult Poles does not eat breakfast every 
day, every fourth does not eat the recommended daily minimum of 3 main meals a day, while only $39 \%$ of adults eat fruit every day. In that respect, the Polish Central Statistical Office data indicate a decline in consumption in 2012 (the most recent available data), the annual consumption per capita was $46 \mathrm{~kg}$ of fruit, nearly $20 \%$ less than in 2002, and for vegetables, the decrease in consumption was $8 \%$ year-over-year [12].

In 2014, a questionnaire survey called Diets of Poles was conducted among 943 persons, constituting a representative random sample of adult Polish citizens. It also demonstrated a significant increase in unhealthy eating habits. Twenty percent of the respondents consumed dinner just before their night rest a couple of times a week, 14\% of the subjects ate salty snacks at least several times a week, and $56 \%$ consumed sweets and pastry, of whom $23 \%$ did so every day [13].

The study demonstrated that in the previous year almost every third Pole used a special diet; $26 \%$ of those diets were elimination diets, which means reducing or eliminating certain products from the diet. The respondents most often reported limiting the consumption, or total exclusion from their menu, of sugar and sweets (55\% of the respondents) and fats (34\%). The subjects specified 3 main motives for controlling their dietary intakes: the desire to lose weight, to obey the principles of healthy nutrition, and to reduce ailments and diseases by following a healthy diet [13].

Other studies, involving different groups of subjects (students, seniors), usually checked the participants' knowledge of the principles of rational nutrition, and were meant to establish the proportion of respondents whose dietary habits/practices were in line with the recommendations $[14,15]$. The WOBASZ study conducted in 20032005 on a representative sample of the general population of Poland, in its fragments referring to people with diagnosed CVDs, also specified only the proportions of the products consumed in quantities corresponding to the guidelines of nutrition experts [16,17].
Unfortunately, no studies have been undertaken to analyze the dietary habits of people with CVDs. Therefore, the aim of this study was to evaluate the dietary behaviors of working people, who were hospitalized due to experiencing the first acute cardiovascular incident.

\section{MATERIAL AND METHODS}

The study was performed in all the patients hospitalized due to the first myocardial incident during 1 year (January-December 2009) in 2 clinics of cardiology in Łódź. The total examined group comprised 1053 subjects. These included 243 men aged $26-70$ years, who were occupationally active before the first cardiovascular incident. Details of the recruitment, procedure and structure of the study were presented earlier [18].

The investigation of the dietary habits formed part of a project intended to determine the profile of occupational and environmental factors of the patients experiencing the first myocardial infarction, and to assess the relationship of those factors with the cardiac incident. The reference group consisted of 403 men aged 35-65 years, who were blue- and white-collar workers of several factories engaged in various activities.

The study was conducted using a questionnaire survey. The research tool was based on the Food Frequency Questionnaire (FFQ) which did not take into account the quantities of the consumed products [19,20]. The questionnaire included 5 questions about the participants' diet: following a special diet, eating main meals regularly, the daily number of main meals, being prone to salty food (adding salt to dishes), and being prone to fatty food. Additionally, the participants filled out a table showing their preferred food ingredients (21 items) and the frequency of consumption (every day, several times a week, occasionally, never).

The quality of nutrition was assessed based on the total scores assigned to the frequency of consumption of 21 products, e.g., for milk, cheese, fruit, vegetables (raw and cooked), and brown bread. Score 4 denoted consum- 


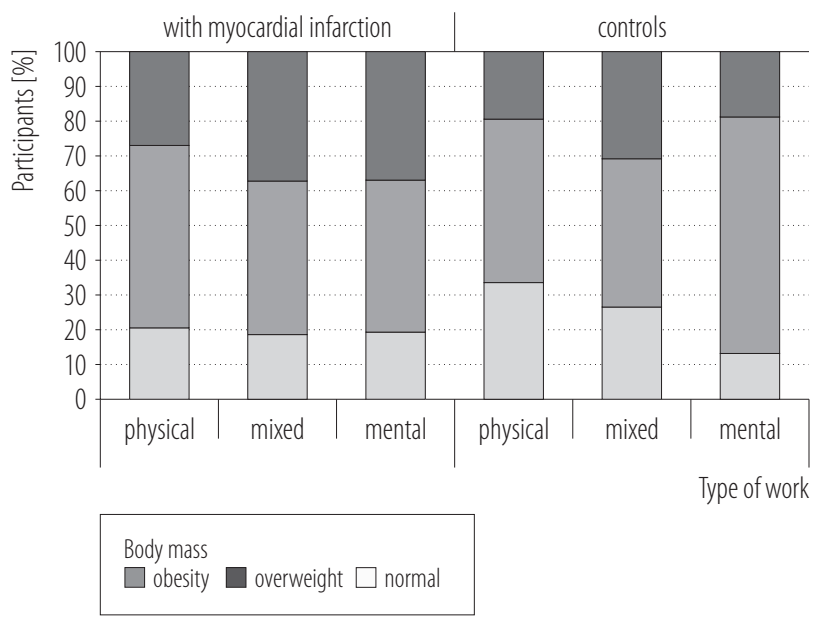

Figure 1. Body weight and the type of work in the group of men occupationally active before the first cardiovascular incident and in the reference group, in the study on dietary habits and myocardial infarction (MI), conducted in 2 clinics of cardiology, Łódź, Poland

ing these products every day, and score 1 - never. This way of assessing the quality of diet has been used in previous studies by the authors [21,22].

The study protocol was approved by the Regional Bioethics Commission of the Nofer Institute of Occupational Medicine in Łódź. The participants were informed about the purpose of the study and gave their written consent to participate in the study.

\section{Statistical analysis}

The frequency of consumption of each product, both among the patients with acute myocardial infarction and in the reference group, was calculated using basic methods of descriptive statistics. Both univariate and multivariate logistic regression models were used to determine the risk factors for myocardial infarction. The frequency of consumption of each product, the number of main meals a day, the preference for fatty or salty foods, and body weight were used as explanatory variables, whereas age, education and the type of work were considered as confounding variables. Odds ratios and $95 \%$ confidence intervals were calculated for all possible risk factors. Then, the multivariate regression analysis was performed to adjust for the effect of confounders. All statistical analyzes were performed using the Statistica version 8.

\section{RESULTS}

Table 1 shows the basic data characterizing both groups of respondents. The men from the reference group were significantly younger than the men with the diagnosis of acute myocardial infarction. Both groups also differed in terms of education and the nature of load at work - the men with higher education and those performing work involving mental load were nearly 4 times more numerous in the MI group compared with the reference group. The body mass index of the MI men was significantly higher. Only approx. 20\% of men with MI were of normal weight, and obesity was reported in $33 \%$ of the patients. The body weight of the subjects was not correlated with age, either in the MI group $(\mathrm{r}=-0.097, \mathrm{p}>0.05)$, or in controls $(\mathrm{r}=0.043, \mathrm{p}>0.05)$.

It was found that among the men with MI, the percentage of people with normal weight, overweight or obesity did not differ depending on the type of work performed. However, in the control group, people with normal weight were the most numerous among people working physically, and the least numerous among those performing mental work $(p=0.016)$, (Figure 1). The men with acute myocardial infarction ate an average of 3 main meals a day, while the men from the reference group ate 2 main meals daily $(\mathrm{p}<$ 0.0001 ). In both groups, the number of main meals did not depend on age or the level of education. As regards the men with MI, the authors found that the number of main meals consumed during the day was significantly lower $(\mathrm{p}=0.002)$ in people doing mental work, compared to those performing physical work. In the control group, those with a mixed load at work consumed significantly fewer main meals than those with physical $(p=0.031)$ or mental ( $p<0.001$ ) load (Figure 2$)$. In the group of patients with myocardial infarction, compared with the reference group, a significantly higher consumption of salty 
$(\mathrm{p}=0.0226)$ or fatty $(\mathrm{p}<0.0001)$ foods was recorded (Table 1).

The frequency of consumption of particular products among the men with MI and in the reference group differed significantly for 11 of 21 products (Table 2). The men with MI reported the daily consumption of fruit, raw vegetables, cheese, vegetable fats, vegetables and fish significantly less frequently than those in the reference group.

Logistic regression was used to test whether the participants' dietary habits affected the MI risk (Table 3). It was found that the MI risk was significantly increased by the reduction of the frequency of consumption of fish, fruit, salads and cooked vegetables. In addition, the MI risk was significantly higher in those people who preferred fatty and/or salty foods. It was shown that, after adjusting for

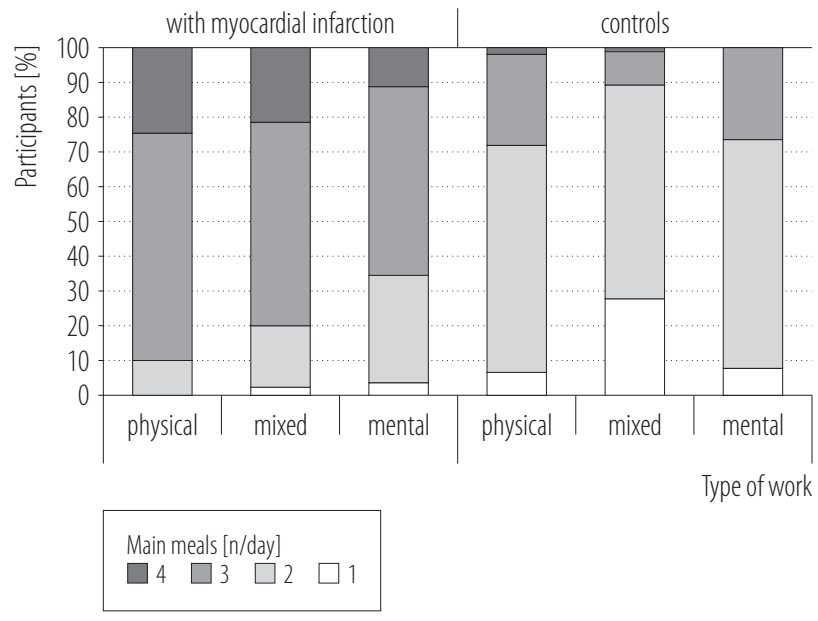

Figure 2. Work and meals in the group of men occupationally active before the first cardiovascular incident and in the reference group, in the study on dietary habits and myocardial infarction, conducted in 2 clinics of cardiology, Łódź, Poland

Table 1. Characteristics of the group of patients involved in the study on dietary habits and myocardial infarction, conducted in 2 clinics of cardiology, Łódź, Poland

\begin{tabular}{|c|c|c|c|}
\hline \multirow{2}{*}{ Variable } & \multicolumn{2}{|c|}{$\begin{array}{c}\text { Participants } \\
(\mathrm{N}=646)\end{array}$} & \multirow{2}{*}{$\mathrm{p}$} \\
\hline & $\begin{array}{c}\text { group 1 } \\
(\mathrm{N}=243)\end{array}$ & $\begin{array}{c}\text { group 2 } \\
(\mathrm{N}=403)\end{array}$ & \\
\hline Age [years] $(\mathrm{M} \pm \mathrm{SD})$ & $52.47 \pm 7.14$ & $46.96 \pm 6.05$ & $<0.001$ \\
\hline Education $[\%]$ & & & $<0.0001$ \\
\hline primary & 46.09 & 62.03 & \\
\hline secondary & 33.33 & 32.75 & \\
\hline higher & 20.58 & 5.21 & \\
\hline Type of work [\%] & & & $<0.0001$ \\
\hline physical & 40.74 & 58.31 & \\
\hline mental & 33.63 & 9.68 & \\
\hline mixed & 36.63 & 32.01 & \\
\hline Body mass index (BMI) $(\mathrm{M} \pm \mathrm{SD})$ & $28.50 \pm 3.92$ & $27.27 \pm 3.89$ & 0.0060 \\
\hline normal body mass $(\mathrm{BMI}<25)[\%]$ & 19.40 & 28.37 & \\
\hline overweight (BMI 25-30) [\%] & 47.84 & 48.58 & \\
\hline obesity $(\mathrm{BMI}>30)[\%]$ & 32.76 & 23.05 & \\
\hline Assessment of body mass* & & & 0.0136 \\
\hline Prone to salty food [\%] & 49.38 & 40.20 & 0.0226 \\
\hline Prone to fatty food [\%] & 56.79 & 38.21 & $<0.0001$ \\
\hline Main meals [n/day] $(\mathrm{M} \pm \mathrm{SD})$ & $2.99 \pm 0.67$ & $2.10 \pm 0.62$ & $<0.0001$ \\
\hline
\end{tabular}

Group 1 - men with myocardial infarction history, occupationally active before the first cardiovascular incident; group 2 - the reference group, blueand white-collar workers of several factories engaged in various activities.

* Tested for normal body mass, overweight and obesity. Significant difference in body weight distribution in groups 1 and 2. 
Table 2. The frequency of consuming food products in the group of men involved in the study on dietary habits and myocardial infarction, conducted in 2 clinics of cardiology, Łódź, Poland

\begin{tabular}{|c|c|c|c|c|c|c|c|c|c|}
\hline \multirow{3}{*}{ Food product } & \multicolumn{8}{|c|}{ Frequency of consumption } & \multirow{3}{*}{$\mathrm{p}$} \\
\hline & \multicolumn{4}{|c|}{$\begin{array}{c}\text { group } 1 \\
{[\%]}\end{array}$} & \multicolumn{4}{|c|}{$\begin{array}{c}\text { group } 2 \\
{[\%]}\end{array}$} & \\
\hline & every day & $\begin{array}{l}\text { several } \\
\text { times } \\
\text { a month }\end{array}$ & occasionally & never & every day & $\begin{array}{l}\text { several } \\
\text { times } \\
\text { a month }\end{array}$ & occasionally & never & \\
\hline Milk, yogurt, kefir & 25.25 & 38.75 & 30.75 & 5.25 & 23.46 & 35.39 & 34.16 & 7.00 & $<0.05$ \\
\hline Cottage cheese & 6.58 & 43.62 & 45.27 & 4.43 & 8.75 & 47.00 & 41.75 & 2.50 & $<0.05$ \\
\hline Cheese & 7.41 & 53.91 & 35.80 & 2.88 & 26.50 & 34.50 & 35.5 & 3.50 & $<0.05$ \\
\hline Eggs & 4.12 & 54.32 & 40.74 & 0.82 & 5.83 & 64.44 & 29.17 & 0.56 & $<0.05$ \\
\hline Meat & 39.51 & 55.56 & 4.94 & 0.00 & 47.25 & 47.75 & 4.50 & 0.50 & $<0.05$ \\
\hline Meats & 53.09 & 40.47 & 5,35 & 0.82 & 46.37 & 49.21 & 3.79 & 0.63 & $<0.05$ \\
\hline Fish & 1.23 & 25.51 & 71.60 & 2.06 & 19.75 & 17.00 & 62.75 & 0.50 & 0.006 \\
\hline Fruit & 36.21 & 39.09 & 24.28 & 0.41 & 51.25 & 37.50 & 9.75 & 1.50 & 0.045 \\
\hline Salads & 16.46 & 57.91 & 24.69 & 1.65 & 28.50 & 54.25 & 16.75 & 0.50 & 0.027 \\
\hline Vegetables & 7.41 & 41.15 & 39.51 & 11.93 & 21.50 & 45.25 & 30.00 & 3.25 & 0.000 \\
\hline Potatoes & 53.09 & 32.51 & 13.17 & 1.25 & 62.25 & 33.00 & 4.75 & 0.00 & $<0.05$ \\
\hline Groats & 11.52 & 35.39 & 46.50 & 6.58 & 3.25 & 14.50 & 61.50 & 20.75 & $<0.05$ \\
\hline Pasta & 4.94 & 56.79 & 37.45 & 0.82 & 10.00 & 55.75 & 33.75 & 0.50 & $<0.05$ \\
\hline White bread & 41.15 & 6.59 & 27.57 & 24.69 & 50.00 & 9.50 & 28.25 & 12.25 & $<0.05$ \\
\hline Whole grain bread & 10.29 & 27.16 & 36.63 & 25.92 & 14.00 & 19.50 & 44.50 & 22.00 & $<0.05$ \\
\hline Jam & 2.88 & 25.51 & 51.85 & 19.75 & 14.00 & 31.00 & 49.50 & 5.50 & 0.022 \\
\hline Candies & 9.05 & 26.75 & 45.68 & 18.53 & 8.50 & 22.00 & 60.25 & 9.25 & $<0.05$ \\
\hline Cakes & 9.88 & 34.16 & 44.44 & 11.52 & 9.25 & 39.00 & 38.25 & 13.50 & $<0.05$ \\
\hline Butter & 51.85 & 13.99 & 19.75 & 14.14 & 41.25 & 16.50 & 22.50 & 19.75 & $<0.05$ \\
\hline Lard & 2.47 & 17.70 & 44.86 & 34.98 & 4.50 & 19.25 & 52.75 & 23.50 & $<0.05$ \\
\hline Vegetable fats & 13.09 & 67.08 & 16.46 & 2.47 & 25.00 & 30.00 & 27.75 & 17.25 & 0.000 \\
\hline
\end{tabular}

Explanations as in Table 1.

age, education and the type of work, the daily consumption of fish, salads and cooked vegetables, as well as fruit and vegetable oils significantly reduced the risk of myocardial infarction. At the same time, the increase in the MI risk was associated with obesity and preference for fatty foods.

\section{DISCUSSION}

In Poland, no studies have been undertaken to analyze the dietary habits of people with CVDs. In 2018, a study was published (PURE Study Poland) on the association between dietary patterns and cardiovascular risk factors in the population of Lower Silesia [23]. However, it con- 
Table 3. The relationship between the first myocardial infarction, dietary habits and body mass - the results of logistic regression analysis (results statistically significant) in the study on dietary habits and myocardial infarction, conducted in 2 clinics of cardiology, Lódź, Poland

\begin{tabular}{|c|c|c|}
\hline \multirow[t]{2}{*}{ Risk factor } & \multicolumn{2}{|c|}{$\begin{array}{c}\text { Risk } \\
\text { OR }(95 \% \mathrm{CI})\end{array}$} \\
\hline & crude & adjusted* \\
\hline \multicolumn{3}{|l|}{ Fish } \\
\hline every day or several times a week vs. & 1 & 1 \\
\hline occasionally or never & $1.625(1.14-2.239)$ & $1.839(1.238-2.732)$ \\
\hline \multicolumn{3}{|l|}{ Fruit } \\
\hline every day or several times a week vs. & 1 & 1 \\
\hline occasionally or never & $2.968(1.906-4.620)$ & $3.019(1.858-4.907)$ \\
\hline \multicolumn{3}{|l|}{ Salads } \\
\hline every day & 1 & 1 \\
\hline several times a month & $1.826(1.200-2.777)$ & $2.202(1.370-3.542)$ \\
\hline occasionally or never & $2.643(1.609-4.343)$ & $2.868(1.627-5.056)$ \\
\hline \multicolumn{3}{|l|}{ Cooked vegetables } \\
\hline every day & 1 & 1 \\
\hline several times a month & $2.640(1.501-4.643)$ & $3.546(1.901-6.615)$ \\
\hline occasionally or never & $4.490(2.553-7.899)$ & $5.107(2.734-9.539)$ \\
\hline \multicolumn{3}{|l|}{ Jam } \\
\hline every day & 1 & 1 \\
\hline several times a month & $4.000(1.719-9.308)$ & $4.908(1.679-10.001)$ \\
\hline occasionally or never & $6.327(2.809-14.254)$ & $5.498(2.379-13.173)$ \\
\hline \multicolumn{3}{|l|}{ Vegetables oils } \\
\hline not everyday & 1 & 1 \\
\hline everyday & $0.488(0.318-0.749)$ & $0.372(0.227-0.611)$ \\
\hline \multicolumn{3}{|l|}{ Prone to fatty food } \\
\hline no & 1 & 1 \\
\hline yes & $2.125(1.536-2.939)$ & $2.214(1.537-3.188)$ \\
\hline \multicolumn{3}{|l|}{ Prone to salty food } \\
\hline no & 1 & \\
\hline yes & $1.451(1.052-2.002)$ & n.s. \\
\hline \multicolumn{3}{|l|}{ Body mass } \\
\hline normal & 1 & 1 \\
\hline overweight & $1.440(0.924-2.245)$ & $1.253(0.807-1.945)$ \\
\hline obesity & $2.051(1.251-3.365)$ & $3.334(1.432-7.763)$ \\
\hline
\end{tabular}

n.s. - not significant.

* Adjusted for age, education and the type of work. 
cerned healthy people and indicated a great importance of dietary patterns in the prevention of CVDs. In this study, the authors found the least favorable dietary habits in comparison with the reference group. The patients with MI significantly less frequently reported the daily consumption of fruit, raw vegetables, cheese, vegetable oils and fish. In this group, the consumption of salty ( $p=$ $0.0226)$ or fatty ( $p<0.0001)$ foods was significantly higher. These differences were significant after adjusting for age, education and the type of work.

In this study, information about nutrition was collected in a simplified way, so the authors did not obtain detailed quantitative information, but merely data on the frequency of consumption of each product. This method was selected because the information was to be collected from patients after myocardial infarction, often in a grave condition, and a long interview was, therefore, contraindicated. Additionally, it is worth noting that the professional method which entails keeping dietary records for a given period (usually 1 or 3 days) did not make sense because of the uniform hospital diet.

A similar method of collecting data on the participants' diet was used in the INTERHEART study [24]. It was conducted in 52 countries and included 12461 people with the first myocardial infarction, and 14637 people without CVDs. The questionnaire assessed the frequency of consumption of 19 categories of food products (e.g., fish, eggs, raw and cooked vegetables, fruit, etc.).

In spite of using a simplified questionnaire, the results of this research and analysis are consistent with the data provided by other authors, regarding the importance of a balanced diet in reducing the MI risk [24-28]. The study showed a lower risk of myocardial infarction in the men reporting an everyday consumption of vegetable oils, and a frequent consumption of fish, vegetables and fruit. There is little available data on the benefits associated only with the consumption of fruit and vegetables. The results obtained by Crowe et al. in 8 European countries revealed that the consumption of 1 portion of fruit and vegetables
(80 g) daily was associated with a $4 \%$ lower risk of death from the ischemic heart disease [29].

The mechanism of the protective effects of fruit and vegetables on the cardiovascular system is not entirely clear. It is speculated that the glycemic index, the low energy density and the content of dietary fiber, potassium, folic acid, etc. may be involved [30]. The consumption of vegetable oil, fish, vegetables and fruit is typical of the Mediterranean diet, which significantly reduces the risk of atherosclerosis and CVDs $[3,31]$. However, the popularity of this diet observed in the population involved in this study was not large - the daily consumption of vegetable oils was reported by approx. one-fourth of the respondents from the reference group, while in the MI group such a frequency of consumption of vegetable oils was reported only by every tenth respondent. Also, the consumption of fish with the frequency recommended by nutrition experts was declared by no more than one-third of the respondents. It is worth noting that an alarmingly high number of the subjects involved in the study, especially those with MI, were overweight (47.8\%) or obese (32.8\%), and only $19.4 \%$ of the men with the myocardial infarction history had normal body mass. The incidence of obesity in the comparable age groups was greater than that reported in the study by Szponar et al. [32] and in the WOBASZ study [33]. These studies, however, were carried out about 10 years earlier than the current study, and the time lag may possibly explain the differences observed in the growing trend of obesity in Poland [34]. According to the recent data in Poland, overweight and obesity occurs in $49.88 \%$ of the population of the Łódź Region, with 52.25\% in the general population [35]. It is generally recognized that excessive (in relation to the energy requirement) energy value of food rations is the primary cause of obesity, while the energy requirement is a resultant of physical inactivity in the first place and, to some extent, of age.

The 10-year prospective study ATTICA (2002-2012) shows that physical inactivity, after eliminating the effects 
of confounders (such as age, sex, smoking habits, cholesterol, and systolic blood pressure) is a significant risk factor for CVDs [36].

The present study also provided interesting information about the importance of other dietary behaviors as risk factors for MI. In this study, the average number of main meals among the patients with myocardial infarction was significantly higher than in the control group (3 vs. 2). The authors did not find similar studies in literature. However, the data published by Giudice et al. indicated a higher prevalence of the carotid atherosclerotic disease in patients consuming $<2$ main meals/day than in those consuming $>2$ main meals/day (96.6\% vs. $85.7 \%$; $\mathrm{p}<0.001$ ) [37].

In the authors' opinion, more plentiful main meals per day give more opportunities to eat too much, which could have been the cause of the more frequent obesity observed in the patients with myocardial infarction.

While the simplified method of gathering information about nutrition, which was employed in this study, made it easier to interview patients, it was not possible to precisely determine the type, and especially the amount, of food products and to calculate the indicators characterizing diets, such as the general caloric value, or the amount of energy contributed by individual product groups, which could be seen as a limitation of this study.

The strength of the study is, however, the presentation of the frequency of consumption of each product and the prevalence of specified dietary behaviors in the patients with myocardial infarction, and the identification of the MI risk factors related to diet, which can be useful in the development of rational dietary guidelines.

\section{CONCLUSIONS}

The authors found that diet significantly modified the risk of MI in the examined workers. This indicates that an important aspect of prevention activities among working people should involve education about proper dietary habits.

\section{REFERENCES}

1. [Food and Nutrition Institute] [Internet]. Warszawa: The Institute 2016 [cited 2016 Mar 1]. [Principles of Proper Nutrition]. Available from: http://www.izz.waw.pl/zasady-prawidowego-ywienia. Polish.

2. Pietinen P, Vartiainen E, Seppänen R, Aro A, Puska P. Changes in diet in Finland from 1972 to 1992: impact on coronary heart disease risk. Prev Med. 1996;25(3):243-50, https://doi. org/10.1006/pmed.1996.0053.

3. Mead A, Atkinson G, Albin D, Alphey D, Baic S, Boyd O, et al. UK Heart Health Group; Thoracic Dietitians Interest Group (Specialist group of the British Dietetic Association). Dietetic guidelines on food and nutrition in the secondary prevention of cardiovascular disease - evidence from systematic reviews of randomized controlled trials (second update, January 2006). J Hum Nutr Diet. 2006;19(6):401-19, https:// doi.org/10.1111/j.1365-277X.2006.00726.x.

4. Schwingshackl L, Hoffmann G. Diet quality as assessed by the Healthy Eating Index, the Alternate Healthy Eating Index, the Dietary Approaches to Stop Hypertension score, and health outcomes: a systematic review and meta-analysis of cohort studies. J Acad Nutr Diet. 2015(5);115:780-800, https:// doi.org/10.1016/j.jand.2014.12.009.

5. Sotos-Prieto M, Bhupathiraju SN, Mattei J, Fung TT, Li Y, Pan A, et al. Changes in Diet Quality Scores and Risk of Cardiovascular Disease Among US Men and Women. Circulation. 2015;132(23):2212-9, https://doi.org/10.1161/CIRCULATIONAHA.115.017158.

6. Menotti A, Puddu PE, Lanti M, Maiani G, Catasta G, Fidanza AA. Lifestyle habits and mortality from all and specific causes of death: 40-year follow-up in the Italian Rural Areas of the Seven Countries Study. J Nutr Health Aging. 2014;18(3):314-21, https://doi.org/10.1007/s12603-013-0392-1.

7. Menotti A, Puddu PE, Maiani G, Catasta G. Lifestyle behaviour and lifetime incidence of heart diseases. Int J Cardiol. 2015;201(15):293-9, https://doi.org/10.1016/j.jijcard.2015.08.050.

8. Menotti A, Puddu PE, Maiani G, Catasta G. Cardiovascular and other causes of death as a function of lifestyle habits in 
a quasi extinct middle-aged male population. A 50-year follow-up study. Int J Cardiol. 2016;210(1):173-8, https://doi. org/10.1016/j.jijcard.2016.02.115.

9. Zdrojewski T, Rutkowski M, Bandosz P, Gaciong Z, Jędrzejczyk T, Solnica B, et al. Prevalence and control of cardiovascular risk factors in Poland. Assumptions and objectives of the NATPOL 2011 Survey. Kardiol Pol. 2013;71(4): 381-92, https://doi.org/10.5603/KP.2013.0066.

10. Zatonski WA, Mc Michael AJ, Powles JW. Ecological study of reasons for sharp decline in mortality from ischaemic heart disease in Poland since 1991. BMJ. 1998;316:1047-51, https://doi.org/10.1136/bmj.316.7137.1047.

11. Zatonski WA, Willett W. Changes population based study in dietary fat and declining coronary heart disease in Poland. BMJ. 2005;331:187-8, https://doi.org/10.1136/bmj.331.7510.187.

12. Central Statistical Office. [Annals of Industry. Statistical Yearbook of Agriculture]. Warsaw: Department of Statistical Publishing; 2013. Polish.

13. Omyła-Rudzka M. [The Communication Research CBOS No. 113/2014]. Warsaw: Diet Poles Foundation for Public Opinion Research Centre; 2014. Polish.

14. Waśkiewicz A, Piotrowski W, Sygnowska E, Broda G, Drygas W, Zdrojewski T, et al. Quality of nutrition and health knowledge in subjects with diagnosed cardio-vascular diseases in the Polish population - National Multicentre Health Survey (WOBASZ). Kardiol Pol. 2008;66(5):507-13.

15. Sipak M, Szych Z, Karolczuk L, Hajduk A, Gorzkowicz B, Owsianowska $\mathrm{J}$, et al. Is the knowledge about their own disorder determines the health behaviors of patients with hypertension. Ann UMCS. 2006;60:32-5.

16. Sygnowska E, Waśkiewicz A, Głuszek J, Kwaśniewska M, Biela U, Kozakiewicz K, et al. Intake of consumed products by adults in the Polish population. Results of the WOBASZ program. Kardiol Pol. 2005;63(suppl IV):670-6.

17. Waśkiewicz A, Sygnowska E, Jasiński B, Kozakiewicz K, Biela U, Kwaśniewska M, et al. The value of a nutritious and energetic diet for adult inhabitants of Poland. Results of the WOBASZ program. Kardiol Pol. 2005;63(suppl IV):663-9.
18. Bortkiewicz A, Gadzicka E, Siedlecka J, Szyjkowska A, Viebig P, Wranicz JK, et al. Work-related risk factors of myocardial infarction. Int J Occup Med Environ Health. 2010;23:255-65, https://doi.org/10.2478/v10001-010-0030-7.

19. Cade J, Thompson R, Burley V, Warm D. Development, validation and utilisation of food-frequency questionnaires a review. Public Health Nutr. 2002;5(4):567-87, https://doi. org/10.1079/PHN2001318.

20. McNutt S, Zimmerman TP, Hull SG. Development of food composition databases for food frequency questionnaires (FFQ). J Food Compost Anal. 2008;21(Suppl):20-6, https:// doi.org/10.1016/j.jfca.2007.05.007.

21. Makowiec-Dąbrowska T, Sprusińska E, Bazylewicz-Walczak B, Radwan-Włodarczyk Z, Koszada-Włodarczyk W. [Work ability: a new approach to assessment]. Med Pr. 2000; 51:317-33. Polish.

22. Makowiec-Dąbrowska T, Koszada-Włodarczyk W, Bortkiewicz A, Gadzicka E, Siedlecka J, Jóźwiak Z, et al. [Occupational and non-occupational determinants of work ability]. Med Pr. 2008;59(1):9-24. Polish.

23. Czekajło A, Różańska D, Zatońska K, Szuba A, Regulska-Ilow B. Association between dietary patterns and cardiovascular risk factors in a selected population of Lower Silesia (PURE Study Poland). Ann Agric Environ Med. 2018;25(4):635-41, https://doi.org/10.26444/aaem/76321.

24. Iqbal R, Anand S, Ounpuu S, Islam S, Zhang X, Rangarajan S, et al. INTERHEART Study Investigators: Dietary pattern and risk of acute myocardial infarction in 52 countries, results of INTERHEART study. Circulation. 2008;118(19):1929-37, https://doi.org/10.1161/CIRCULATIONAHA.107.738716.

25. Hu FB, Willet WC. Optimal diets for prevention of coronary heart disease. JAMA. 2002;288(20):2569-78, https://doi.org/ 10.1001/jama.288.20.2569.

26. Jankovic N, Geelen A, Streppel MT, de Groot LC, Kiefte-de Jong JC, Orfanos P, et al. WHO guidelines for a healthy diet and mortality from cardiovascular disease in European and American elderly: the CHANCES project. Am J Clin Nutr. 2015;102(4):745-56, https://doi.org/10.3945/ajcn.114.095117. 
27. Holme I, Retterstøl K, Norum KR, Hjermann I. Lifelong benefits on myocardial infarction mortality: 40-year follow-up of the randomized Oslo diet and antismoking study. J Intern Med. 2016;280(2):221-7, https://doi.org/10.1111/joim.12485.

28. Eckel RH, Jakicic JM, Ard JD, de Jesus JM, Houston Miller N, Hubbard VS, et al. American College of Cardiology/ American Heart Association Task Force on Practice Guidelines. 2013 AHA/ACC Guideline on Lifestyle Management to Reduce Cardiovascular Risk. A Report of the American College of Cardiology/American Heart Association Task Force on Practice Guide. Circulation. 2014;129(25 suppl 2): 76-99, https://doi.org/10.1161/01.cir.0000437740.48606.d1.

29. Crowe FL, Roddam AW, Key TJ, Appleby PN, Overvad K, Jakobsen MU, et al. European Prospective Investigation into Cancer and Nutrition (EPIC)-Heart Study Collaborators, Fruit and vegetable intake and mortality from ischaemic heart disease: results from the European Prospective Investigation into Cancer and Nutrition (EPIC)-Heart study. Eur Heart J. 2011;32(10):1235-43, https://doi.org/10.1093/eurheartj/ehq465.

30. Bazzano LA, Serdula MK, Liu S. Dietary intake of fruits and vegetables and risk of cardiovascular disease. Curr Atheroscler Rep. 2003;5(6):492-9, https://doi.org/10.1007/s11883003-0040-z.

31. Hoevenaar-Blom MP, Nooyens AC, Kromhout D, Spijkerman AM, Beulens JW, van der Schouw YT, et al. Mediterranean style diet and 12-year incidence of cardiovascular diseases: the EPIC-NL cohort study. PLoS One. 2012;7:454-8, https://doi.org/10.1371/journal.pone.0045458.
32. Szponar L, Ciok J, Dolna A, Ołtarzewski M. [Policy options for responding to the growing challenge from obesity a cross-national comparative study. Polish National Report]. Warsaw: Food and Nutrition Institute; 2006. Polish.

33. Biela U, Pająk A, Kaczmarczyk-Hałas K, Głuszek J, Tendera M, Waśkiewicz A, et al. [Incidence of overweight and obesity in women and men between the ages of 20-74. Results of the WOBASZ program]. Kardiol Pol. 2005;63(suppl IV): 632-5. Polish.

34. Jarosz M, Rychlik E. Overweight and obesity among adults in Poland, 1983-2005. Adv Med Sci. 2008;53:54-6, https:// doi.org/10.2478/v10039-008-0048-2.

35. [Potrafisz schudnąć] [Internet]. Warszawa: Business Target Group Polska Sp. z o.o. 2013-2015 [cited 2016 Mar 1]. [Report: current statistics of obesity and overweight in Poland based on the interactive maps obesity in Poland, state on the second quarter of 2015]. Available from: https://potrafiszschudnac.pl/mapaotylosci/lipiec2015-grudzien2015. Polish.

36. Georgousopoulou EN, Panagiotakos DB, Bougatsas D, Chatzigeorgiou M, Kavouras SA, Chrysohoou C, et al. Physical Activity Level Improves the Predictive Accuracy of Cardiovascular Disease Risk Score: The ATTICA Study (2002-2012). Int J Prev Med. 2016;7(1):52, https://doi.org/ 10.4103/2008-7802.178346.

37. Giudice R, Izzo R, Manzi MV, Pagnano G, Santoro M, Rao MA, et al. Lifestyle-related risk factors, smoking status and cardiovascular disease. High Blood Press Cardiovasc Prev. 2012;19(2):85-92, https://doi.org/10.1007/BF03262458.

This work is available in Open Access model and licensed under a Creative Commons Attribution-NonCommercial 3.0 Poland License - http://creativecommons.org/ licenses/by-nc/3.0/pl/deed.en. 